\title{
On the puzzling value of human life
}

\section{Predrag Cicovacki}

\begin{abstract}
The author examines our conflicting attitudes regarding the proper value of human life. While the main issue initially appears to deal with whether or not human life has an intrinsic (or absolute) value, it turns out that a far more important and complex issue concerns the tension between the equal value of every human life and the differences in the quality of one's life. The author discusses the views of Kant, Schweitzer, Berlin, Scheler, and then Hartmann, in whose views the author recognizes the most important contributions to this puzzle.
\end{abstract}

Keywords: antinomies of values, equal value of human lives, intrinsic value, quality of life

\section{A challenge}

Regardless of our culture, gender, or age, we display incompatible attitudes toward the value of human life. Sometimes we go out of our way to fight for and preserve every single life; other times we are completely indifferent to the fact that people who could be saved are left helplessly dying. We display the same ambiguous attitude toward our own lives: in some cases it appears that they are more valuable to us than anything else, while in other circumstances we are ready to sacrifice our lives for some higher values.

It would be unreasonable to claim that human life has no value whatsoever, yet when it comes to establishing precisely what value it does have, we do not know what to say. This perplexity may not be accidental; it may be an indication of our inability to demonstrate the value of human life in any conclusive manner. Or it may be an indication of the complex nature of the value of life, and perhaps of other values as well. It remains to be seen which of these is the case. What is already clear is that we are facing a challenge. To deal with it, let us focus our inquiry on the following four statements:

1. Every human life has an intrinsic (or absolute) value.

2. No human life has any intrinsic (or absolute) value.

3. Some human lives are more valuable than others.

4. No human lives are more valuable than others.

We can schematically represent them as follows (figure 1): 


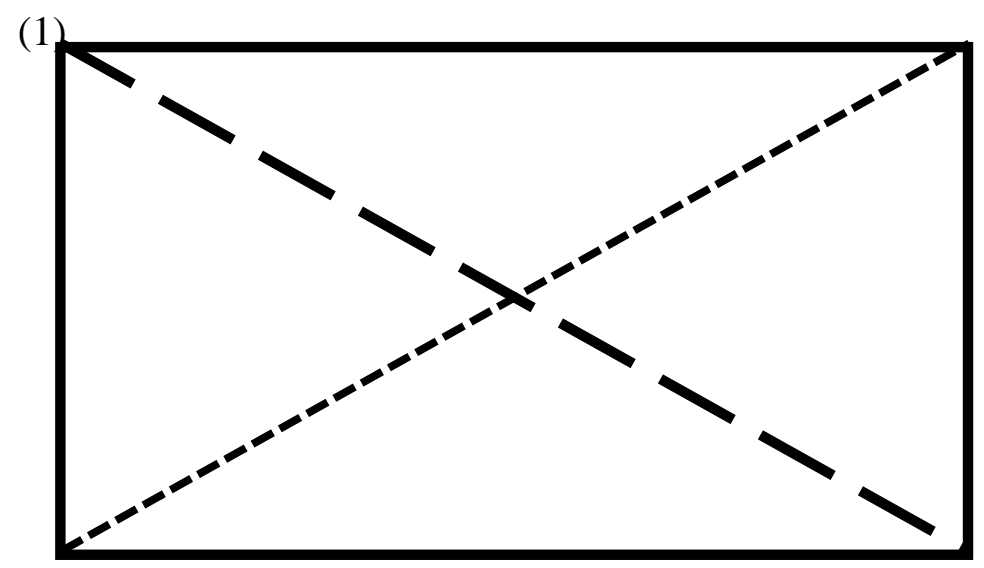

(2)

(4)

Let us briefly clarify the meanings of the contested claims. By value of something we mean its worth; however that worth is to be specifically defined. To say that a value of something is intrinsic is to maintain that it is desirable and esteemed for its own sake, for its own inherent qualities. Similarly, a value of something is absolute if it is never relative upon any further condition, restriction, consideration, or circumstance. Can such an intrinsic and absolute value be justifiably ascribed to human life? (Indeed, can anything have such a value?)

Our initial reactions are probably going to be ambiguous, for such a claim appears both intuitively evident and too strong. Following the history of the twentieth century - which is often called the century of wars and genocides - we would like to affirm that all human life is valuable in itself. This holds not only for extraordinary human beings, or even for every normal and healthy person. Indeed, it holds for every human being: a prematurely born baby that is going to live only for a few hours, a starving child in India or Somalia, a homeless person on the streets of New York or San Francisco, or a person suffering from Alzheimer's disease, dying secluded in some nursing home. Every one of them is unquestionably valuable and every one of them should be given a chance to live and die with dignity. Inspiring thoughts, but irritating doubts always find their way to creep in: What could possibly rationally justify the view that every human being is so sacred and of unquestionable value?

If we are willing to admit that, prima facie, every human life is a value and death is a disvalue, what other value but intrinsic or absolute could we wish to ascribe to human beings? In his book, An Analysis of Knowledge and Valuation, C. I. Lewis distinguishes between the following values: (a) utility or usefulness for some purpose; (b) instrumental value (of means); (c) inherent value (or goodness); (d) intrinsic value (or being desirable as an end or in itself); (e) contributory value, relevant for our understanding of the relationship of parts and whole (Lewis, 1971, pp. 382-397). While these distinctions are useful in many contexts, they are not of much help for our discussion. Clearly, we are not going to claim that the value of human life is any variety of (a), (b), or maybe even (e). But on what grounds can we argue in favor of (c)? Perhaps, most importantly for our discussion, how can we establish (or refute) that (d) is the case?

Before we attempt to answer these questions, we should be aware of three potential ambiguities. The first is that value is usually ascribed to objects and acts: we say that a book has some (determinable) value, and that giving it as a gift to someone is a valuable act. Yet, life 
cannot be counted as either an object or an act. This anomaly may be one source of our difficulties, but it may also lead to unexpected new insights.

The second point is not to confuse the so-called 'vital values' - such as health, energy level, life-enthusiasm, and so on - for the 'value of life'. Vital values deal with values vital for life, while our topic is about the value of life.

The third thing is to remember that what we are asking is not merely whether we should regard human life as inherently and intrinsically valuable; for our interpersonal relations it is very useful that we do regard each other in that way. Yet, just as there is a meaningful distinction between taking something to be true and its truth, and the two need not overlap, we are concerned with a similar distinction: Does human life really have such an intrinsic and absolute value?

\section{An intrinsic value of human life?}

The central issue with regard to our challenge seems to be dealing with the conflict between (1) and (2): Does human life have an intrinsic (or absolute) value, or does it not?

There are two principal grounds on which the positive view has been traditionally supported: the religious and the moral. Considering the religious grounds first, it is plausible to argue that the central message of the Gospel is the sanctity of all human life. Yet, why would that be? Does the Gospel reveal some undeniable facts about human nature on the basis of which a special value of human life can be derived? Is there something about the origin of humanity that would automatically reveal its preciousness? Furthermore, if this line of reasoning about the sanctity of human life is taken seriously, then why not go a step further and claim, together with Albert Schweitzer, that not only human life but all and any life is precious? As God created human life, He created all other life.

Schweitzer's religiously inspired ethics of reverence for life - Ehrfurcht vor dem Leben asserts that good consists in maintaining, assisting and enhancing life, and that to destroy, to hurt, or to hinder life is evil. Reverence for life is the most direct achievement of what Schweitzer called 'my will-to-live': "I am life which wills to live, in the midst of life which wills to live" (Schweitzer, 1987, p. 309).

While Schweitzer's line of reasoning appears admirable, it has found few adherents. We can agree with him that life is more valuable than death, and that we should avoid unnecessary destruction of human and all other life. Yet, reverence for the miracle of all life can be taken seriously without thereby implying that all life is sacred, or that it has an intrinsic and absolute value. Not surprisingly, Schweitzer himself was the first to recognize that, in order to preserve and enhance some life, other lives must be destroyed. Thus, his principle is primarily directed against our mindless and often unnecessary destruction of life (Schweitzer, 1987, pp. 310-314; Cicovacki, 2012, pp. 58-80).

Moreover, if we come to the point of arguing that not only human life but all life is sacred, why not make an even bolder step and maintain that every creature, everything that exists, is precious and sacred? The reason for not doing so is simple and compelling. Despite a deeply embedded Augustinian (and to a certain extent Platonic) tradition, 'being' does not imply 'goodness' and 'non-being' does not imply 'evil'. More generally, 'existence' does not imply 'value', and 'non-existence' does not imply 'disvalue'. By the same token we can claim that 'life' does not imply 'value', and 'death' (or 'absence of life') does not imply 'disvalue'. Our great teacher Socrates had taught us long ago that fear of death is irrational and that only good life (and not sheer life) is worth living.

We may thus be advised to check whether claim (1) can be supported on some other, perhaps moral, grounds. Kant argues, for instance, that every human being is an end in itself and that it 
should never be treated as a means only. This so-called second formulation of the Categorical Imperative offers one of the strongest supporting arguments for the view that human life has an intrinsic and absolute value, but it also leads to numerous questions and concerns. Kant is right to claim that the value of human life should not be considered in terms of instrumental values alone; but is he thus right to ascribe an intrinsic value to human life?

Suppose that we indeed approach the world with the noble ideal that every human being is an end in itself and treat every person accordingly. Like the Christian precept to love our neighbors as we love ourselves, the implementation of Kant's Categorical Imperative would probably make the world a better place, yet it would also lead to some maddening dilemmas. There is no problem in treating our neighbors who behave reasonably and morally as ends in themselves. But should we treat murderers, rapists, and terrorists in the same manner? Should we treat them as rational moral agents even when they apparently behave both irrationally and immorally?

To be fair to Kant, he himself wavers between praising humanity as an end in itself and complaining that "[from] such crooked wood as man is made of nothing perfectly straight can be built" (Kant, in Beck, 1988, p. 419). He never successfully reconciles these conflicting views, nor is it an easy task to accomplish. Kant would have perhaps strengthened his cause had he distinguished between the value of human life in general, and the value of human life in concreto. The latter is a matter of specific appraisal and cannot be resolved by any a priori decree. But what should we say about the value of human life in general? Just as in his theoretical philosophy Kant tries to put an end to what he calls a 'scandal of reason' by offering conclusive proof of the existence of the external world, in his practical philosophy he attempts to remove an analogous scandal by demonstrating an intrinsic (and absolute) value of human life.

Perhaps Kant's approach is misguided in both cases. We do not really need proof of the existence of the external world, because the presupposition of its existence belongs to the very framework of any intelligent discourse and is necessarily presumed for any cognitive experience. It may similarly be beyond the power of our mind to prove that being human is of some ultimate, intrinsic or absolute, value. But such proof may not be needed either. The value of human existence seems intuitively obvious to us.

We have feelings for values. It is true that such feelings may be more or less developed, and that their accuracy and depth may vary. It is also true that the presence of such feelings does not demonstrate that the value of life is intrinsic; at best, it only indicates that such a value may exist. This is significant not only because it helps us establish a respectful attitude toward other human beings, but also because of the function this value has in our overall 'valuational' experience: the value of human existence belongs to the framework within which all other values could be experienced and evaluated.

As a value, human life may well be indefinable, but it provides a presupposition for the realization of other values, and perhaps also a framework within which different kinds of values e.g., pleasure values, goods as values, vital values, spiritual values, and values of the holy - may be related, assessed, and realized. This may not be what we initially looked for in order to support claim (1), but it may be one element of the view yet to be fully developed and appreciated.

\section{At the crossroads}

Just as we, in Western civilization, have, from our Christian heritage, developed the attitudes of compassion and high esteem for every human life (claim 1), we can trace our strong support for the view that some human lives are more valuable than others (claim 3) to our Greek ancestors. With their ethics of aspiration, the ancient Greeks were preoccupied with striving toward virtue and excellence. As philosophers like Socrates, Plato, and Aristotle understood it, the task was not 
so much to compete against others, thereby making ourselves better than them. Rather, it was to compete against ourselves and to become as good as we could possibly be. Instead of an 'egalitarian' Christian ethics (based on e-quality), the Greeks believed that we should endorse an ethics based on merit (or quality).

We can strongly object to their parochial division between 'civilized Greeks' and 'uncivilized barbarians', as well as reject their treatment of some human beings as 'slaves by nature'. Nevertheless, we can rationally maintain that, in terms of numerous specific values, some human lives are, indeed, more valuable than others. We are different not only in terms of innate capacities and gifts, but principally in how far and how completely we develop and exercise them. How we live cannot be disregarded, for those ways of life make our lives more or less valuable. The quality of life must be taken into consideration when we discuss what value human life may have.

We have now arrived at the central crossroads in our complicated aporia concerning the value of human life. The real challenge does not consist in the opposition of (1) and (2), but of (1) and (3). The central question with regard to this axiological aporia is whether to accept one of the competing claims, or whether any such acceptance of either one of them may be so extreme and unsatisfactory that a proper response to the challenge calls for some kind of reconciliation of (1) and (3). Schematically, we can present this situation as follows (figure 2)

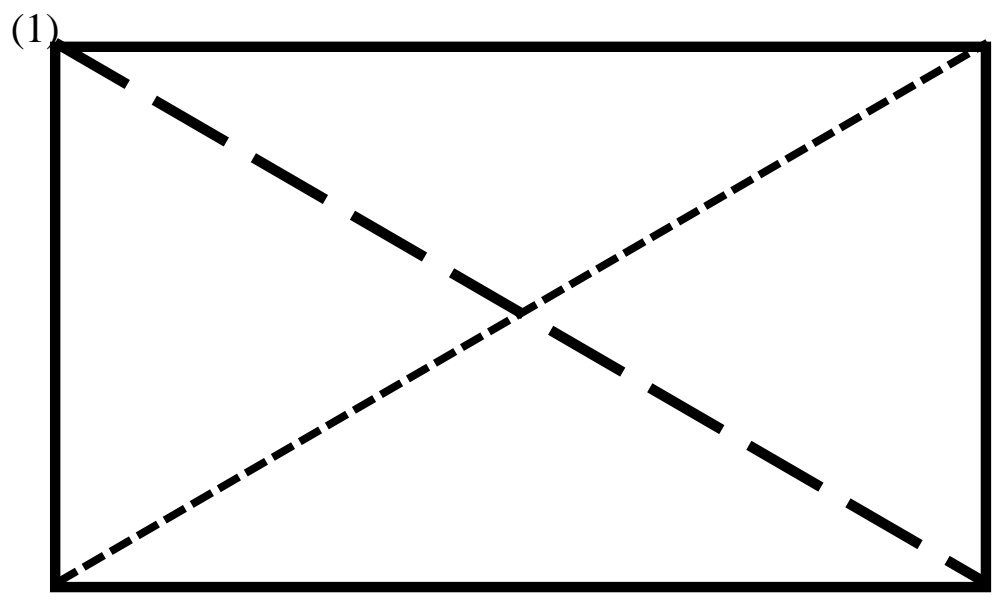

(3)

(2)

Let us first consider the reasons for choosing either (1) or (3). It appears that, just as a consistent Christian would be opposed not only to (2) but also to (3), a consistent advocate of the Greek ethics of aspiration would have to dispute not only (4), but (1) as well. The reason for this discrepancy could be seen from a more general distinction between 'having a value' and 'being given a value': if all things were in themselves valuable, there would be no sense in any attempt to enhance value. Thus, the tension between the view that every human life has an intrinsic and absolute value and the view that some human lives are more valuable than others is a real one; this controversy characterizes not merely our age but belongs to the very core of our Western civilization. 
As the tension between claims (1) and (3) is real and important, so are the various attempts to resolve it. Even though Christianity clearly favors (1) over (3), its own rich and complex tradition indicates a number of ways in which they can be reconciled. One of them includes a simultaneous emphasis on mercy and compassion on the one hand, and the essential for our humanity project of the imitatio Dei on the other. For an illustration of this we can again turn to Schweitzer. Following Jesus, he believed in the affirmation of all life. But inspired by Goethe and Nietzsche, who in turn were inspired by the pagan ancient Greek tradition, Schweitzer also believed in a continuous effort toward ennoblement; our ideal must be to deepen our moral life and express it in moral action.

Kant similarly believed, if not in the Grounding for the Metaphysics of Morals and Critique of Practical Reason, then certainly in his later work Metaphysics of Morals, that our two fundamental goals in life are the perfection of ourselves and the happiness of others. It has always been perceived as an undeniable aspect of human nature to strive toward what is noble and good, toward the highest values and aspirations. Taken in that sense, the view that some lives are more valuable than others (claim 3) is more intuitive and seems to need less rational grounding than the view that every human life has an intrinsic (or absolute) value (claim 1). Nevertheless, taken to an extreme, this view may lead to something like Nietzsche's devaluation of all 'pity' and the reaffirmation of the Greek pagan ideal of excellence in terms of his Übermensch. Such an extreme view appears intuitively mistaken, as mistaken as its counterpart, which denies any morally relevant sense in which human lives may not all be of equal value.

\section{Scheler's scale of values}

Claims (1) and (3) stand in clear opposition to each other. Taken in isolation and driven to an extreme, they are not only one-sided but unsatisfactory. Is there any hope that, despite their opposition and our tendency to swing from one extreme position to another, they may be reconcilable? Max Scheler's view on values may offer a solution.

For (1) and (3) to be compatible, some kind of commensurability between these rival claims would be needed; the main issue, then, concerns finding a suitable ground for their potential and fruitful commensurability. Minimally, we need to assume that both of them may be true, and then to show how both can be true in different domains, or in different ways. From there, the crossroads lead in different directions. One of them, pursued by Scheler, shows that there is a unified, or one-dimensional, scale of values by means of which the value of human life can be precisely determined. (The second direction will be discussed in the next two sections.)

Scheler believes in an objective order of higher and lower values and tries to establish a onedimensional scale that could reveal the exact ranking of each value. He is convinced that "the hierarchy of values is itself absolutely invariable, while the order of preference in history is what is variable" (Scheler, 1973, p. 106.) Scheler comes to realize, however, that no matter how that scale is constructed, we always run into counterintuitive examples: the value of human life cannot be permanently and unchangeable situated either at the top of the hierarchy of values, or at its bottom, or somewhere in the middle.

Scheler attempts to address this problem by proposing a number of additional categories and by formulating a complicated 'law of preference', but his successors abandoned his project. Although every human life is prima facie valuable, can we properly estimate the value of each life without taking into account its deeds and attitudes? And when we do take them into consideration, we run into a plurality of values, some apparently incompatible with others, and with no definite hierarchy. The value of human life may be not only indefinable but also indeterminable in any a priori manner. If so, this would account for both the richness of human 
life and the bewildering difficulties in properly estimating its worth. Can we, then, make any further progress beyond the realization of the plurality and complexity of values?

A paradoxical thing about Scheler is that, despite his conscious effort precisely to establish the value of human life, he would in many ways welcome his critics' concerns; they may well be consistent with some other of his fundamental views. For instance, in opposition to Kant's rigid formalism, Scheler's moral theory is based on the view that our experience of values is not discrete but contextual. Rarely, if ever, is a value given in isolation from other values, and we always evaluate things within the given situational background, as well as within the background of our own social and personal experience. A lot must be known before a choice can be rationally made, and even when as much as possible is known, the tip of the scale may still stand pretty close to a dynamic equilibrium, or it may not even be clear in which direction it points. Of course, in practical life, a choice has to be made, for even a refusal to choose is to make a decision that carries with it significant implications and consequences. Whatever choices we end up making, we are not only in a double bond but in a double bind as well.

Some moral philosophers may be disappointed by this line of reasoning and insist that moral theories are designed to tell us how, in principle, we ought to act and what kind of attitude we ought to assume toward our lives and the lives of others. Why should we not, then, expect a more principled theoretical solution when there is a conflict between (1) and (3)?

Scheler's reply may be that we can still offer a variety of 'maxims' and 'rules' of prudence concerning how to treat our own lives and the lives of others, but this need not bring us any closer to a principal solution to our problem. For if we reject - as Scheler believes we should - all moral theories that postulate absolute obligations or prohibitions, no moral theory could regulate all possible cases. As he points out, theories and norms are too abstract and remote from actual ethical situations; they are disembodied and impersonal, too detached from the dynamic of real life.

Instead of looking for some 'regulate-it-all' moral theory, then, we may be better off searching for some principles of rational value-preference, something akin to what is nowadays called a theory of rational decision. Trying to improve on Scheler's view, one of Husserl's students, Hans Reiner, proposed a more detailed approach to issues of value-preference, which he presented through the following eleven principles:

1. Value-height, as developed in Scheler's ethical approach.

2. Value-urgency, by which Reiner means that those values that are of greater 'ontic' urgency must be realized first. (For example, securing one's physical survival is more urgent than realizing higher values and will take precedence in many situations.)

3. Temporal urgency: other things being equal, values in danger require immediate attention.

4. The greater or more pressing need.

5. Quantity of value-realization: other things being equal, we ought to aim at the greatest quantity of values.

6. The greater chance of success.

7. The negative demand of not violating already existing values usually has priority over the positive demand of realizing new values.

8. A person can be obliged to perform one task rather than another if there is a scarcity of people who can do the job equally well.

9. Special abilities and the possession of particular means for performing certain tasks can present a personal call and impose a unique obligation on an individual. 
10. If a person is more gifted for one task rather than for another, he/she may have a special calling to choose that undertaking which he/she can do his/her best and in which he/she will perform best.

11. The principle of daimonion: when all of the mentioned ten principles of valuepreference prove to be insufficient to reach a clear and correct decision, 'a voice of conscience', or a particular personal 'daimonion' (as in Socrates' case), may have to function as the decisive principle of decision (Reiner, 1951, pp. 168-178).

Although valuable, this proposal is not without visible shortcomings. For instance, principles 2-4 cluster together and, just like principles 8-10, may be regarded as variations of the same principle. Furthermore, missing from Reiner's list is any consideration of the predicable short and long run consequences. These, however, are not of vital concern for us now. The essential point is that, regardless of what we think of the proposed principles and however useful as tools they may be, the burden of reaching an informed and proper decision is still on us. What is right in principle need not be appropriate in specific circumstances, and vice versa. Our human lives and the conflicting situations we encounter are so diverse and intricate that no theoretical tool can remove the onus of making decisions from our shoulders. And this holds for the puzzling issues concerning the value of human life as well.

This lack of a principled position on the value of human life may be the result of a subject's indecisiveness, or of one's inability to think about the issues in question in a systematic and thorough manner. Or, more importantly, and due to no fault of the judging subject, it may be the result of a realistic assessment of human nature and the complex place and role that human life plays in reality. Our very nature may be too convoluted; we may be simultaneously pulled in many different directions and attracted to incompatible values, so that an adequate principal position is not possible. It need not be the values themselves that are obscured, nor does it always have to be our imperfect vision of them. It may be that choosing between them, and choosing rightly, is what is so difficult - and so distinguishably human.

This position is championed by Isaiah Berlin, who recognizes the irreconcilable oppositions of some fundamental values, such as equality and liberty, order and tolerance, justice and mercy. ${ }^{1}$ Berlin perceives this predicament in very pessimistic terms. We are doomed to choose, and every choice may entail an irreparable loss: "[I]f, as I believe, the ends of men are many, and not all of them are in principle compatible with each other, then the possibility of conflict - and of tragedy - can never be wholly eliminated from human life, either personal or social” (Berlin, 1969, p. 169).

Does the conflict of values have to lead to such pessimistic implications? Not so, according to a fascinating, although undeservedly neglected, approach which we find in Nicolai Hartmann's Ethik. $^{2}$ In this masterpiece, first published in 1926, Hartmann accepts that there are countless conflicts of values. Nevertheless, together with the plurality of values and their conflicts, Hartmann also recognizes (i) their absoluteness, (ii) mutual irreducibility, (iii) partial incompatibility, and (iv) their potential synthesis.

\footnotetext{
${ }^{1}$ A similar position was defended by Max Weber and Robert Nozick.

${ }^{2}$ What is, in German, originally published as one book, is available in the English translation as three separate books: Moral Phenomena, Moral Values, and Moral Freedom (Hartmann, 2002; 2003; 2004).
} 


\section{Hartmann's account of values}

Following Scheler, Hartmann maintains that values are essences, in the phenomenological sense of that word. Values possess the character of genuine essences, that is, the character of absoluteness, and any knowledge of them can be no other than aprioristic knowledge. This is possible because values have their own ideal existence: their realm is not that of the real but of the ideal being. That means, among other things, that values are not only independent of things that are estimated as valuable, but are their prerequisites: things can be valuable only through a relation to values themselves. It also means that values are equally independent of persons: they cannot make or create values, nor do values change as a result of a person's insights. The socalled relativity of values with regard to our subjective experience of them affects only the content but not the structure of values (Hartmann, 2002, pp. 232-244; Hartmann, 2014, pp. 367368).

Against Scheler, Hartmann maintains that our understanding of values in general, and of the worth of human life in particular, can be further advanced if we recognize a two-dimensional scale of values. In accord with his ontological views, instead of one kind of 'bond' between values (respective height), Hartmann contends that values can be meaningfully contrasted not only in terms of their respective height but also with regard to their strength (Hartmann, 2003, pp. 44-64).

Like the ontological strata of reality - and Hartmann distinguishes between four of them: the inorganic, the organic, the psychic, and the spiritual - values are structured from the bottom up. Stronger values serve as a foundation for weaker values, but the positive reinforcement of stronger values does not thereby bring higher values into existence. Higher values have at least partial autonomy with regard to their lower counterparts. The key point for Hartmann is that, analogous to the relationship of the strata of the real being, the highest values are the weakest, and that the strongest values are the lowest. Higher and weaker values are dependent for their realization on the realization of lower and stronger values. Lower values are thus the conditio sine qua non of higher values and become 'matter for them', their 'clay to be shaped'. Despite such conditioning, the specific form of such shaping is introduced by higher values and cannot be predetermined by lower values.

On Hartmann's view, the value of human life in general definitely belongs among the most basic and foundational, that is, the strongest and the lowest values. Higher values are those of the personal subject, and they are not universal but individual values. The strength and relevance of the strongest values is expressed through prohibitions, and it is not accidental that virtually every society considers murder of other human beings as one of the worst crimes. Hartmann's important insight is that there is an asymmetry with respect to violation versus positive reinforcement of values: although murder is among the worst kind of violations, respect for life does not thereby automatically represent a very high value. Put differently, a violation of a lower value is a greater offense than a violation of a higher value. Nevertheless, a realization of a higher value is more valuable than a realization of a lower value (Hartmann, 2003, pp. 27-28, 53, 453454).

Hartmann formulates this relationship as the 'inverse law of strength and height', which fully captures the double bond of values: evidence of their strength is found in the seriousness of the offense against a value, while their height is known by the meritoriousness of fulfillment. Our moral project can be summed up like this: do not violate the stronger values and aspire to realize the higher values (Hartmann, 2003, p. 457).

Where does this approach leave us with our concerns about the value of human life? First, it makes us aware not only of the plurality but also of the interconnectedness and 
multidimensionality of values. More specifically, it cautions us against thinking of human life in terms of one single value that could be artificially isolated and separately defined. There are many values we associate with human life, and this richness is also indicated through the difference between two relevant expressions: 'human being' and 'being human'.

Claim (1) is closer to the former expression and claim (3) is more focused on the latter. 'Human being' (like 'human life') refers to something that is given, a datum of a kind, while 'being human' refers to a task - it points to the incompleteness and under-determinacy of the datum. Moreover, it poses a challenge to us. Human beings have a strong desire not only to live but to live well; ours is a deep awareness of the insufficiency of sheer living, and the question for us is not only whether to live but how to do it. Provided that the existence is granted, there could hardly be any alibi for failing to try, as seriously as we can, to bring about that which we consider to be good, beautiful, and true. Different cultures and viewpoints would understand this task of self-realization of our humanity in diverse ways. As already mentioned, our Christian and Greek ancestors certainly conceived of it in different fashions. As a result of such differences, we have inherited internally conflicting ideals and value systems.

There are different reasons for conflicts of values. The most obvious among them is an enormous plurality of values; in what is, in English, published as the second volume of his Ethik, Moral Values, Hartmann considers more than forty different values (cf. Hartmann, 2003; Cicovacki, 2014, pp. 65-136). Although values can be systematically analyzed, they cannot be arranged on the single scale of values. Instead of one single valuational scale which ascends in one unified series or a pyramid of values with one highest value on the top in Hartmann we find a network of multiple, frequently mutually dependent but also inconsistent values.

When he speaks about such inconsistencies and conflicts of values, Hartmann does not have in mind an opposition between one positive and one negative value (as in (1) and (2), or (3) and (4)). We usually choose among what we find valuable, so the real conflicts of values are either those between two positive values (as in (1) and (3)), or between two negative values. To be even more precise, the conflicts of values we experience can be either the conflicts of values themselves $\left(\mathrm{V}_{1} \mathrm{vs} . \mathrm{V}_{2}\right)$, or the conflicts of various valuational situations in which we attempt to actualize values $\left(\mathrm{VS}_{1}\right.$ vs. $\left.\mathrm{VS}_{2}\right)$.

Only the conflicts of values themselves $\left(\mathrm{V}_{1}\right.$ vs. $\left.\mathrm{V}_{2}\right)$ can lead to what Hartmann calls 'antinomies of values'. He offers numerous examples of such antinomies, but for our present purposes it suffices to mention just a few: the communal versus the individual, with a related conflict of the general equality of all human beings as standing against the inequality which characterizes every person. Yet another example would be the perennial tension between justice and brotherly love. As we all know, "justice may be unloving, brotherly love quite unjust" (Hartmann 2003, p. 271).

Hartmann's most original treatment of the antinomies of values is to be found in his view that there are four equally fundamental and mutually irreducible moral values: the good, the noble, rich in experience, and the pure. The good is characterized by our attempts to convert values into ends. The noble is the value of the pursuit of one value to the exclusion of all others. Richness of experience is the value of personal many-sidedness, including some things that cannot be estimated as good, and is radically opposed to the one-sidedness of the noble. Like nobility, purity is also founded on single-mindedness and opposed to the richness of experience; unlike the noble, purity is predicated upon obliviousness of the conflict and opposition inherent in a good and noble character (Hartmann, 2003, pp. 171-222).

In addition to pointing out that these four fundamental moral values are not mutually consistent, Hartmann furthermore maintains that the entire realm of values is characterized by 
ineradicable anatomies between values. Human beings reveal their character through the ways in which they tackle these ever renewing and multiplying antinomies of life. Life itself presents the greatest challenge for man as a spiritual and valuational being: "moral life is life in the midst of conflicts" (Hartmann, 2003, p. 94).

Like Berlin, Hartmann maintains that there is no pre-given schema to determine how such antinomies of values should be handled; in facing the conflicts and antinomies of values, every individual has to rely on his or her own sense of value and make personal preferences. Hartmann surprises us when, unlike Berlin, he points out that the existence of antinomical tensions is by itself something valuable; such tensions keep our discernment and the feeling of value alive and help it further develop.

Unlike Socrates, who continually battles against our ignorance and misconceptions, Hartmann is more focused on the narrowness of our 'value-horizon': most of us virtually sleepwalk through life, oblivious to its complexity and depth, indifferent toward the richness of values. Hartmann sharply criticizes our blindness toward the higher values which have impoverished us and prevented us from living authentic human lives. For a value-blind man, everything ultimately becomes worthless, even what is in itself of value. For the open-hearted man, on the contrary, everything is valuable, even what in itself in contrary thereto. There is certainly no other way to ethical maturity and expansion than through the conflicts of life itself, through 'moral experience' - even experience of wrong-doing, and this perhaps most of all (Hartmann, 2003, p. 209).

Conflicts and antinomies of values are not something tragic, since they help us to awaken our value-feelings and sharpen our value-intuitions; they convey to us a sense of amazement and respect for a cosmos rich with values. Hartmann is a genuine pluralist with regard to values, but not a relativist. He believes in the universality, necessity, and objectivity of valuational judgments. But not everyone has the eye, the ethical maturity, and the spiritual development required for grasping the structural relations of values and for judging the valuational situations as they are (Hartmann, 2002, pp. 38-45; Hartmann, 2014, pp. 359-368). The maieutic function of philosophy is thus to free us not only, or perhaps not so much, from ignorance, as from our 'passing by values' in blindness of them.

Besides pointing to the strength and height, as two respective ways of comparing values, Hartmann also discusses the idea of synthesis of values. While Berlin laments what he calls 'the incommensurability of values', Hartmann reminds us that no single value exists for itself; rather, every value finds its fulfillment only in its synthesis with other values, and - finally - in one Idea, in one synthesis of all values. ${ }^{3}$ Such synthesis is not something given, but is an ideal toward which we must strive: "Only a sense of justice which is at the same time loving, only a brotherly love which also considers the far distant, only a pride which would likewise be humble, could be valid as an ideal of moral conduct" (Hartmann, 2003, p. 425).

In our moral thinking, no less than in our moral practice, we tend to pursue single values, which are often taken to extremes. Hartmann warns us that such extremes serve only to distort our sense of values and to misguide us toward one-sidedness. The real challenge is to ground our moral and spiritual lives on a solid foundation of lower values, and then pursue higher values, for only in the synthesis of strong and high values can we find the reciprocal content of both types of values. To discern their synthesis, however, is a task of far greater magnitude than to attach oneself to one side and disregard the other: "The secret of human progress is that advance must

\footnotetext{
${ }^{3}$ According to Hans-Georg Gadamer, who was Hartmann's student at the time when he wrote Ethik, Hartmann thought that his most important contribution to axiology may be his idea of synthesis of values (Gadamer, 1999, pp. 27-28).
} 
be along the whole line, and not by fragments, that the trend towards the highest must be accompanied by a trend toward the most elementary. Every other progress is only a semblance. It surrenders on one side what it wins on the other" (Hartmann, 2003, p. 463).

\section{In lieu of a conclusion}

Hartmann does not offer a simple reply to our challenge to determine the value of human life. His findings are nevertheless valuable not only because of their originality, but also because they help us to discern our proper place and role in reality. According to Hartmann, the puzzling and complex nature of the value of human life is a reflection of the puzzling and complex nature of values in general. More specifically, Hartmann's findings could be summed up as follows:

(a) Life is a value and death is a disvalue. Life is not created by human beings, but it exists, it is real, and it is given to us; life is (as if) entrusted to our care.

(b) We may overestimate the value of life (e.g., when health is taken as the highest good, a vital value is then promoted too high, beyond its proper measure). We may also underestimate its value (e.g., when all value is carried over into the life beyond, as in asceticism, or in religious fanaticism).

(c) There is a value peculiar to life itself, and it may well be an intrinsic value. An intrinsic value does not, however, have to be the highest value.

(d) Life itself is not the highest value, but it is a very significant value; it is a foundation of all higher values. The value of life would not lapse if it were not linked up with some higher values, e.g., values of spiritual existence. Nonetheless, life gains in a decidedly higher significance from the connectedness with such spiritual values.

According to Hartmann, there is a fundamental antinomy in the nature of values, which consists in the claims to validity that go in two opposite directions: our unconditional preference for the higher is restricted by an equally unconditional preference for the lower and more fundamental values. The art of living consists in finding a proper balance between the claims that pull us in these different directions. His views could be represented by the following figure (figure 3):

(2)

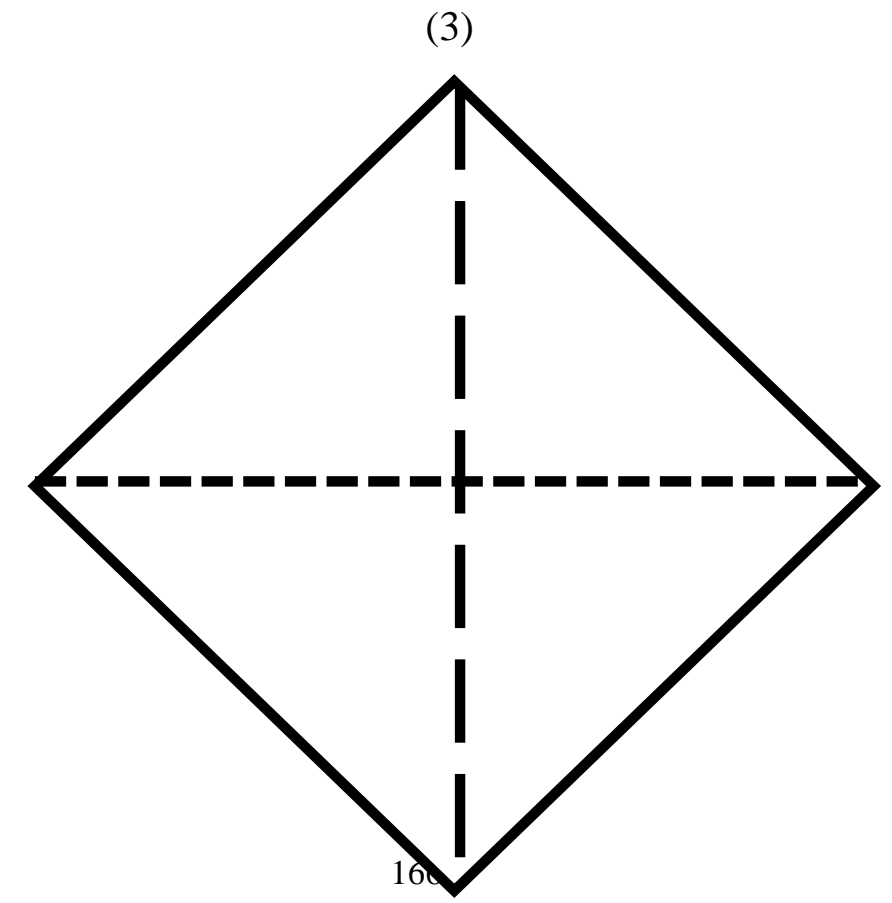


While (1) refers to the value of life (existence) itself, and (3) refers to the quality of life, (2) and (4) in this figure are not their negations, but other positive values (such as justice, brotherly love, courage, truthfulness, trust, etc.) that make the transition from sheer life to the quality of life possible. Although never used by Hartmann himself, this figure captures his view that there is something good in each of us, and that we all strive, in our own way, toward what is great and superior. Hartmann is convinced that we strive toward them from the bottom of our nature, and he maintains that this is the most beautiful feature of humanity.

While Hartmann undoubtedly offers a very original and stimulating conception of values and their conflicts, there is much more that could and should be discussed before a final judgment can be passed on the value of his theory. Most of them deal with his views regarding the antinomies of values and a potential synthesis of values. For example, Hartmann mentions numerous antinomies of values, but some systematization of their tensions must also be developed: Are they all antinomical on the same grounds and for the same reasons? Are they all equally antinomical? Are they all equally incommensurable? Even when there are no principal resolutions of such antinomies, there must be practical resolutions: how can we decide which of them are better and which are worse? Furthermore, if the whole idea of the synthesis of values does not resolve their antinomies, what exactly is the point of such a synthesis? How realistic is Hartmann's idea of one ultimate synthesis of all values? Is it (to use Kant's language) a 'constitutive' or a 'regulative' idea? What is gained if such a synthesis is possible, and what is lost if it is not?

My hope is that my discussion will stimulate further study of Hartmann's provocative theory of values which may, in turn, lead to our better understanding of the puzzling value of human life.

Predrag Cicovacki was born in 1960 in Belgrade, Serbia where he later obtained his B.A. in Philosophy. After receiving his Ph.D. in Philosophy at the University of Rochester in 1991, he has been teaching philosophy at the College of the Holy Cross. He is the author and/or editor of seventeen books. His current research is in the philosophy of love and nonviolence.

\section{Corresponding author:}

Predrag Cicovacki, Department of Philosophy, College of the Holy Cross, Worcester, MA 01610, USA.

Email: pcicovac@holycross.edu

\section{References}

BECK, L. W. (1988): Kant-Selections. New York: Macmillan.

BERLIN, I. (1969): Four Essays on Liberty. Oxford: Oxford University Press.

BERLIN, I. (2000): The Proper Study of Mankind: An Anthology of Essays. New York: Farrar, Straus and Giroux.

BERLIN, I. (2013): The Roots of Romanticism. Princeton: Princeton University Press.

CICOVACKI, P. (2012): The Restoration of Albert Schweitzer's Ethical Vision. New York: Continuum.

CICOVACKI, P. (2014): The Analysis of Wonder: An Introduction to the Philosophy of Nicolai Hartmann. New York: Bloomsbury.

EDMUNDSON, M. (2015): Self and Soul: A Defense of Ideals. Cambridge, MA: Harvard University Press.

GADAMER, H-G. (1999): Hermeneutics, Religion, and Ethics, trans. J. Weinsheimer. New 
Haven, CN: Yale University Press.

HARTMANN, N. (1962a): Das Problem des geistiges Seins. Berlin: de Gruyter.

HARTMANN, N. (1962b): Ethik. Berlin: de Gruyter.

HARTMANN, N. (2002): Moral Phenomena, trans. Andreas A. M. Kinneging. New Brunswick, NJ: Transaction Publishers.

HARTMANN, N. (2003): Moral Values, trans. Andreas A. M. Kinneging. New Brunswick, NJ: Transaction Publishers.

HARTMANN, N. (2004): Moral Freedom, trans. Andreas A. M. Kinneging. New Brunswick, NJ: Transaction Publishers.

HARTMANN, N. (2014): Aesthetics, trans. E. Kelly. New York: Walter de Gruyter.

IRWIN, W. B. (2009): A Guide to the Good Life. Oxford: Oxford University Press.

KANT, I. (1996): Practical Philosophy, trans. Mary J. Gregor, ed. A. Wood. New York: Cambridge University Press.

KOLNAI, A. (2008): Ethics, Value \& Reality. New Brunswick, NJ: Transaction Publishers.

KRZNARIC, R. (2011): How Should We Live? Katonah, NY: Blue Books.

LEWIS, C. I. (1971): An Analysis of Knowledge and Valuation. La Salle, IL: Open Court.

LIN, Y. (1998): The Importance of Living. New York: William Morrow.

NOZICK, R. (1983): Philosophical Explanations. Cambridge, MA: Belknap Press.

REINER, H. (1951): Pflicht und Neigung. Meisenheim/Glan: Westkulturverlag Anton Hain.

SAMUELSON, S. (2014): The Deepest Human Life: An Introduction to Philosophy for Everyone. Chicago: University of Chicago Press.

SCHELER, M. (1973): Formalism in Ethics and Non-Formal Ethics of Values, trans. M.S. Frings \& R.L. Funk. Evanston, IL: Northwestern University Press.

SCHELER, M. (1979): Man's Place in Nature, trans. H. Meyerhoff. New York: Noonday Press.

SCHELER, M. (1992): On Feeling, Knowing, and Valuing, ed. Harold J. Bershady. Chicago: The University of Chicago Press.

SCHELER, M. (2008): The Nature of Sympathy, trans. P. Heath. New Brunswick, NJ: Transaction Publishers.

SCHWEITZER, A. (1987): The Philosophy of Civilization, trans. C. T. Campion. Amherst, NY: Prometheus Books.

SCRUTON, R. (2014): The Soul of the World. Princeton: Princeton University Press.

SOWELL, T. (2002): A Conflict of Visions. New York: Basic Books.

TAYLOR, R. (2002): Virtue Ethics: An Introduction. Amherst, NY: Prometheus Books.

WEBER, M. (2002): The Protestant Ethic and the Spirit of Capitalism, trans. P. Baehr \& G. C. Wells. New York: Penguin. 